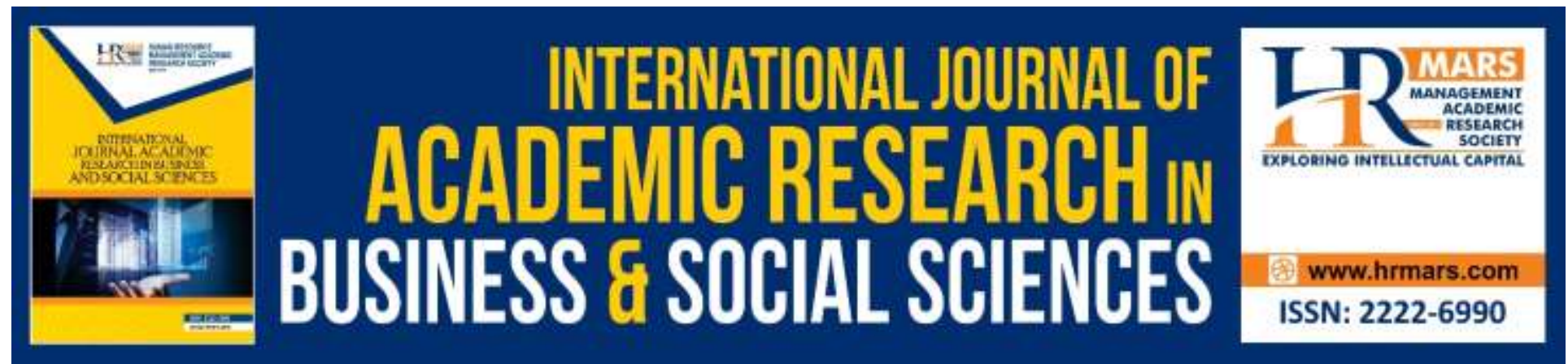

\title{
Morphological Patterns of Personal Naming Practice: A Case Study of Non-Concatenative Arabic Language
}

\section{Abdelrazzaq Tahat}

To Link this Article: http://dx.doi.org/10.6007/IJARBSS/v10-i6/7333

DOI:10.6007/IJARBSS/v10-i6/7333

Received: 25 March 2020, Revised: 13 May 2020, Accepted: 10 May 2020

Published Online: 30 June 2020

In-Text Citation: (Tahat, 2020)

To Cite this Article: Tahat, A. (2020). Morphological Patterns of Personal Naming Practice: A Case Study of NonConcatenative Arabic Language. International Journal of Academic Research in Business and Social Sciences, 10(6), 572-585.

Copyright: (c) 2020 The Author(s)

Published by Human Resource Management Academic Research Society (www.hrmars.com)

This article is published under the Creative Commons Attribution (CC BY 4.0) license. Anyone may reproduce, distribute, translate and create derivative works of this article (for both commercial and non-commercial purposes), subject to full attribution to the original publication and authors. The full terms of this license may be seen at: http://creativecommons.org/licences/by/4.0/legalcode

Vol. 10, No. 6, 2020, Pg. 572 - 585

http://hrmars.com/index.php/pages/detail/IJARBSS

JOURNAL HOMEPAGE

Full Terms \& Conditions of access and use can be found at http://hrmars.com/index.php/pages/detail/publication-ethics 


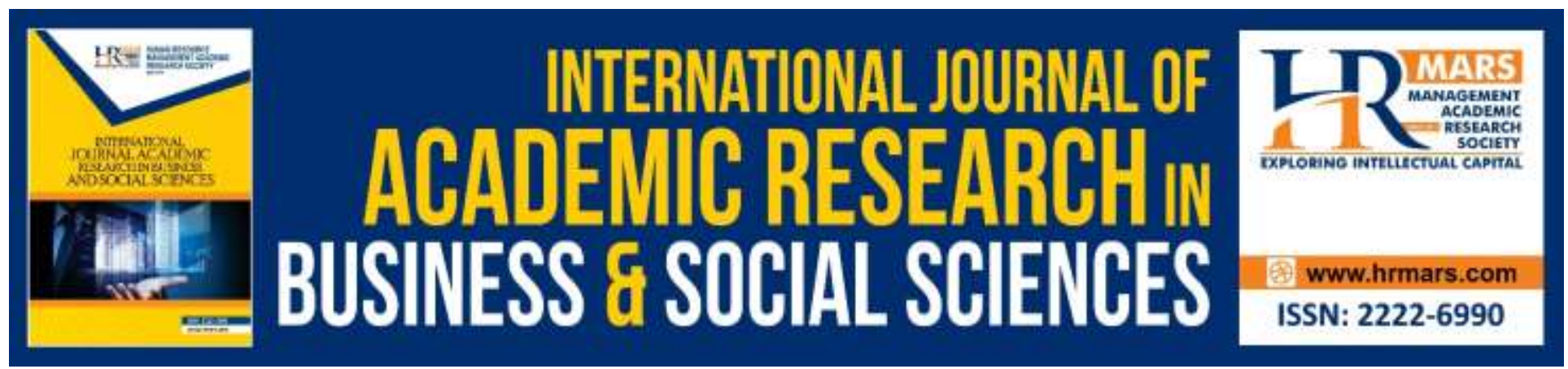

\title{
Morphological Patterns of Personal Naming Practice: A Case Study of Non-Concatenative Arabic Language
}

\author{
Abdelrazzaq Tahat \\ School of Languages, literacies \& translation, Universiti Sains Malaysia, 11800 Pulau Pinang \\ Malaysia \\ Email: tarma15_hum022@student.usm.my.
}

\begin{abstract}
The type pf a personal name and the language system to which these names adhere to are two very significant components to determine the morphological pattern of a personal name. Arabic is a synthetic fusional language that allows morphological operations to be applied to the root itself as non-concatenative operations involved. This survey of morphology is precisely focused on the different ways of analyzing and describing the morphological patterns that Jordanian personal names follow through their formation process relying on the derivational and inflectional approaches. conventionally, we referred to the associations that make up various parts of lexeme as morphological patterns; thus, the current analysis revealed and identified the patterns in which Jordanian personal names fall including derivation processes; verbal nouns derived from trilateral, quadrilateral, and quinquiliteral verb roots, compounding, diminutivization, and reduplication; in addition to the inflectional processes including pluralization and personal names inflected for gender. It is quite obvious that Jordanian personal names could be morphologically classified as derived and inflected names besides each patterns involves a set of word's structure operations that mark a name as derivationally or inflectionally formulated.
\end{abstract}

Keywords: Morphological Pattern, Arabic Language, Jordanian Personal Names, Item-AndProcess Theory.

\section{Introduction}

Generally speaking, the classification of languages is divided into groups according to some specific given features (Aronoff and Fudeman, 2010). These parameters could be the order of language elements i.e. words order which involve the syntactic features, how sounds are articulated and used in the phonological system, and the morphological types a given language has or lack in its structural system (Comrie, 1989). However, this study will concentrate on the 
typology of personal names according to the morphological features in order to identify Jordanian personal names' morphological patterns. Morphologically, languages are either analytical or synthetic based on their word's structure system (Comrie, 1989). Arabic is a fusional non-concatenative synthetic language permits morphological operations applied to the root itself according to some abstract patterns, and also allows derivational and inflectional processes to form new words (Muhammad, 2006). The aforementioned is highly significant to open the floor and determine the path to investigate the morphological patterns the study aiming to answer because morphological patterns are applied to a set of associations that build the different forms of lexeme (Anindo, 2016).

During the analysis of Jordanian personal names morphologically, the name's root is used as the base to which the formation process of personal names refer, and that root is actually the basic unit stored in the lexicon of Arabic. According to Bybee (1988) IP theory is mainly relying on the morphological analysis of word based on root as morpheme and other morphological operations applied later. In line with El Zarka (2005) root in Arabic language constitutes the base for derivation process. Moreover, the analysis of corpora show that changes in the root itself led to a formation of new personal names that carry specific meaning according to the derivation process and type of change occurred to the root. An example can be seen in the case of reduplication where initial, internal, or final consonant reduplicated of the root form new personal name. In other words, IP theory accounts for the formation of new word based on the possibility of analyzing root and determining the position undergone changes. In this point, the changes are considered morphologically not phonologically as argued by some linguists (Hurch and Mattes, 2005; Marantz, 1982) because the units doubled in reduplication are described in terms of morphology, a bare consonant or a root, to bring about a new grammatical function.

\section{Methods}

Linguistic analysis of personal names requires a collection using a corpus of names. In order to investigate the morphological patterns of Jordanian personal names and the internal structure of word's formation process, to apply the morpheme-root analysis based on the Item-andProcess morphological theory, a quite enough number of these names are required. To do so, the researcher collected a number of personal names as can be seen in table 1 via a questionnaires. Respondents were asked to mention the names of their children and other names were also collected from the interviewees in the interview sessions.

\section{Derivational and Inflectional analysis}

The morphological analysis of the collected personal names will be done using dashes (-) to help provide an in-depth explanation and understanding of the structure of these names. The morphological pattern of personal names is a set of all operations and rules that may apply to create the forms of lexemes. In order to investigate the patterns of Jordanian personal names, the analysis will be carried out with reference to derivational and inflectional operations that are covered with the structure of names in question in order to identify and describe the patterns of personal names. In word formation processes, words have two main stages derivational or inflectional ones to form other words from one category to another. According to Endang (2014), the meaning of derivational morphemes is bound morphemes which derive (create) new words by either changing the meaning or the part of speech or both. 
Whereas, inflectional morphemes never change the syntactic category of the words or morphemes to which they are attached. By the first stage of derivational morphemes, words are combined with a stem, change either the meaning or part of speech of the affected word; in other words, changing a noun to a verb in the process of word formation. In Arabic for instance, in the word jatabadal, the changing of the bound morpheme ja by derivational prefix mu in mutabadel changes the word from a verb (change) to a noun (interchange). On the other hand, inflectional morphemes modify number, tense, or gender without affecting the word's meaning or category (Widdowson, 1996; O'Grady et al, 1996; and Frumkin et al, 2007). Examples of applying inflectional morphemes are adding feminine inflectional suffix /a/taa marbuuTa to the Arabic male personal name Sameer to form Sameera or male name zameel to female name zameela means beautiful. This is known as inserting inflectional suffixes. Inflections are affixes that can be added to words in the form of prefixes or suffixes and sometimes infixes according to the language where these names or words are used. Hence, this research aims at looking on the process of how morphemes are joined together to form, for instance, male and female names through the morphological processes to identify morphological patterns during the process of name's formation.

Nevertheless, there are basic elements that make up the grammar of any language such as verbs, adjectives, and nouns. These major elements would help determine and ease the investigation of language's internal structure such as to look at the nature of morphological rules applied. The distribution of these elements to the current study is represented in table 1That is to say, the number of personal names belongs to each verbal, nominal, or adjectival base.

TABLE 1. The distribution of grammatical element making up the Jordanian personal names

\begin{tabular}{lcc}
\hline Base & Number of personal names & Percentage \\
\hline Triliteral verbal root & 76 & $25 \%$ \\
Quadriliteral and & 44 & $14 \%$ \\
Quinquiliteral & & \\
Verbal root & & \\
Nouns & 166 & $55 \%$ \\
Adjectives & 18 & $6 \%$ \\
Total & 304 & $100 \%$ \\
\hline
\end{tabular}

Table 1 shows that the majority of personal names collected are derived from nouns with a percentage of $55 \%$ followed by triliteral verbal root $25 \%$, quadriliteral and quinquiliteral $14 \%$, and adjectives $6 \%$. Morphologically analyzing the structure of these personal names according to the category they were derived from, we will be able to gain a profound understanding to the rules of word's formation process and thus identifying the morphological patterns that Jordanian personal names embedded.

\section{Results}

\section{Verbal Nouns}

Verbal nouns refer to all nouns that are derived from their corresponding verbs. The nouns derived including personal names as illustrated below have various patterns based on the verb they are derived from such as triliteral, quadrilateral, or quinquiliteral verbs. For personal names 
derived from triliteral verb root, they showed a kind of regularity in the derivation process in that two morphological patterns have constantly been identified as either the insertion of a consonant and vowel to the root or the replacement of long aa in the root with a conjunctive Hamza in the derived personal name. However, this finding contradicts with Harrama (1993) in that nouns derived from triliteral verb roots are featured with irregularity, and it is a bit difficult to predict the pattern of the derived noun accordingly. With regard to personal names derived from quadrilateral and quinquiliteral verbal root, they mainly followed a consonant-vowel CV deletion of the verb root to the insertion of derivational morpheme mu to the derived name. In addition, the last short vowel $a$ in the verb's template is replaced with $\mathrm{i}$ also at the same position of the derived personal name.

Table 2. Triliteral root (Past verb form)

\begin{tabular}{|c|c|c|c|}
\hline No & Verb gloss & $\begin{array}{c}\text { Personal name } \\
\text { formation }\end{array}$ & $\begin{array}{c}\text { Personal name } \\
\text { meaning }\end{array}$ \\
\hline 1 & Sa+ra+f (to have knowledge) & Sa+ri+f & knowing \\
\hline 2 & $X a+l a+d$ (to & $X a+l i+d$ & immortal \\
\hline 3 & $\hbar a+m a+d$ (to praise) & $\hbar a+m i+d$ & Who praise \\
\hline 4 & $\mathrm{Ba}+\mathrm{sa}+\mathrm{m}$ (to smile) & $\mathrm{Ba}+\mathrm{si}+\mathrm{m}$ & Smiley person \\
\hline 5 & $a+d a+l$ (to be fair) & Sa+di+l & Impartial \\
\hline 6 & $w a+\lceil a+d$ (to promise) & $w a+9 i+d$ & Promising \\
\hline 7 & Saa+da (became common) & Sa?d & Prominent \\
\hline 8 & Qaa+da (to lead) & qa?d & Leader \\
\hline 9 & Raa+fa (to show mercy) & rapf & Merciful \\
\hline 10 & Raa+da ( & ra?d & Pioneer \\
\hline
\end{tabular}

Table 2 shows that personal name can also be derived from triliteral verb root i.e. past verb form. This type of verbs in Arabic is known as a pattern morpheme which is defined as the insertion of consonants and vowels in an abstract template (Habash et al., 2005). This template is represented as CVCVC where $C$ stands for consonant and V for vowel. Personal names derived from this triliteral root keeps the same template structure as CVCVC except for the replacement of short vowel (a) between the second and third consonant of the root to (i) fatha and kasra in Arabic, respectively.

This in turn proves that the template from which personal names are derived is an abstract template that only allows vocalic replacement. For example, personal name Sarif is derived from the triliteral verb root Saraf where the derived name has undergone only vowel shifting to the vowel position stated above from fatha to kasra. However, some triliteral roots involve the long aa sound taking the pattern CVV+CV such as Saa+da and when deriving a personal name the long aa is replaced with conjunctive Hamza as noted in Sa?d to avoid the sukuun interface in Arabic due to the difficulty in pronunciation that would occur by the sukuun interface. 
INTERNATIONAL JOURNAL OF ACADEMIC RESEARCH IN BUSINESS AND SOCIAL SCIENCES

Vol. 10, No. 6, June, 2020, E-ISSN: 2222-6990 @ 2020 HRMARS

Table 3. Quadriliteral and quinquiliteral roots (Present Verb Form)

\begin{tabular}{|c|c|c|c|}
\hline No & Verb gloss & $\begin{array}{c}\text { Personal name } \\
\text { formation }\end{array}$ & $\begin{array}{c}\text { Personal name } \\
\text { meaning }\end{array}$ \\
\hline 1 & ja + smaћ (to forgive) & Mu + samih & $\begin{array}{l}\text { Forgiver, } \\
\text { excuser }\end{array}$ \\
\hline 2 & ja + Stasim (to refuge) & $\mathrm{Mu}+\Upsilon_{\text {tasim }}$ & To refugee \\
\hline 3 & ja + hjjb (to magnify) & $M u+h j j b$ & $\begin{array}{l}\text { Magnificent } \\
\text { person }\end{array}$ \\
\hline 4 & ja + ntasir (to win) & $\mathrm{Mu}+$ ntasir & Winer \\
\hline 5 & ja + tawala (to take care of) & Mu + tawali & $\begin{array}{c}\text { Person } \\
\text { responsible for }\end{array}$ \\
\hline 6 & ja $+\int$ taq (to miss) & $\mathrm{Mu}+\int \mathrm{taq}$ & $\begin{array}{l}\text { Who miss } \\
\text { someone } \\
\text { something }\end{array}$ \\
\hline 7 & ja + hwis (to make troubles) & Mu + hawif & Trouble maker \\
\hline
\end{tabular}

Table 3 shows verbal noun derivation process of personal names from both quadriliteral and quinquiliteral verb roots. Personal names that are derived from present verb form in both roots' forms are constructed by the deletion of the parsing present marker ja and replacing it with the derivational morpheme Mu that shows the active participant ism al-faall in Arabic. The root of the present verb remains the same in the derivation process except for the inversion of short vowel (a), fatha in Arabic into a short vowel (i), kasra for the derived personal name. For example,

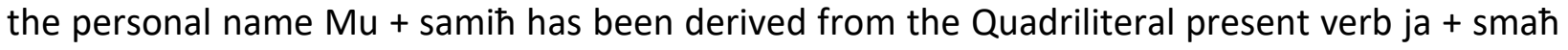
to forgive by the deletion of ja the present verb form marker \{alamt \amudar $\uparrow a$ and the insertion of mu the active participant marker ism al-faaৎl. In addition, the short vowel a in the verb form has been shifted to short vowel $i$ to express the act of doing i.e. the person who forgive and excuse others. 
Table 4. Personal Names Formed through Compounding Tarkiib Process

\begin{tabular}{|c|c|c|c|}
\hline No & Personal name & $\begin{array}{c}\text { Compounding } \\
\text { formation }\end{array}$ & $\begin{array}{c}\text { Personal name } \\
\text { meaning }\end{array}$ \\
\hline 1 & Siz aldiin (male name) & $\mathrm{N}:$ Siz + N: aldiin & Might of the religion \\
\hline 2 & Sala aldiin & Sala +aldiin & Nobility of the religion \\
\hline 3 & Sabdu allah & Sabdu + Allah & Servant of Allah \\
\hline 4 & Sabdu alraћman & Sabdul + raћman & $\begin{array}{l}\text { Servant of the } \\
\text { merciful }\end{array}$ \\
\hline 5 & Pum KalOuum (female name) & Pum + KalOuum & A cheeky soft woman \\
\hline 6 & Pmal alhaya & Pmal + alhaya & Hope of life \\
\hline 7 & yuSn alban & yuSn + alban & $\begin{array}{l}\text { Branch of Alban(type } \\
\text { of trees) }\end{array}$ \\
\hline 8 & PalmuStasim biAllah & $\begin{array}{l}\mathrm{N}: \quad \text { PalmuStasim+Pre: } \\
\text { bi+ N:Allah }\end{array}$ & Refuge to Allah \\
\hline 9 & Palmu?min biAllah & $\begin{array}{l}\mathrm{N}: \text { PalmuPmin +Pre: bi+ } \\
\mathrm{N} \text { :Allah }\end{array}$ & Believer in Allah \\
\hline
\end{tabular}

In table 4 compounding Tarkiib in Arabic is a word formation process that involves composing a word by conjoining other words (Ryding, 2005). It is found from the data that it is not necessary for lexical items created through compounding process to be a single word but rather can be a noun phrase NP. Actually, NP revealed from the data is a nominal construct NP which consists of two nouns as a constituent. The first noun is called the construct head PalmuĐaf, while the second noun is the inner NP PalmuĐaf Pilyh to which the second name is added (Hoyt, 2008). The corpora of personal names show that they are formulated through a combination of two nouns for male and female names and grouped under NP class. For example, the male personal name Siz aldiin is formed by the combination of the construct head noun Siz and the inner NP aldiin. The female personal name um KalOuum is also formed of the construct head noun um and the inner NP KalӨuum the same as in the male personal name formation.

Table 5. Personal Names Formed through Diminutivization

\begin{tabular}{lll}
\hline No & \multicolumn{1}{c}{ Personal name } & \multicolumn{1}{c}{ Diminutive personal name form (1) } \\
\hline 1 & Salim (CVCVC) & Sweelim (CCVVCVC) \\
2 & Samir & Sweemir \\
3 & Salih & Sweelih
\end{tabular}

Common noun

Diminutive personal name form (2)

4 Puðun (CVCVC)

?uðayna (CVCVCCV)

5 Pumam Pumayma

As can be seen in table 5 the personal names collected are only five names showing diminutivization; three of them are male personal names 1-3, and the remaining two are female personal names 4-5. Based on these corpora, it shows that diminutivization is not that productive process in personal names formation though it might be so productive in other classes' derivations such as in place name which is known as toponymes or brand names, for instance. 
For the current collected personal names, two diminutive forms can be identified from the personal names in table.... The first form is singular personal name transformed into diminutive personal name such as Samir into \weemir. This form is mainly based on the insertion of the consonant waaw with vowel shifting to ee immediately after the first consonant of the singular personal name (CVCVC) maintaining the pattern (CCVVCVC) in the three examples of Sweelim, Sweemir, and Sweelih. On the other hand, diminutive female personal names are not derived from singular personal name but rather from common nouns such as in the case of ?uðun ear and Pumam nations. Both of these common nouns are feminine nouns in Arabic bared from the feminine marker taa Palta?ne $\theta$. Nevertheless, in this form of diminutive personal names the derivation occurred by the insertion of bound morpheme ya between the second and third consonant in the base common noun and the reversion of feminine marker taa ?alta?ne $\theta$ to the derived diminutive female personal name. This can be identified in the structure of the diminutive name ?uða+yn+a and also in ?uma+ym+a. it is worthy to highlight here that the a added to the diminutive name represents taa ?alta?ne $\theta$ because it is pronounced as a not taa in spoken Arabic.

Table 6. Personal Names Formed through Reduplication

\begin{tabular}{llc}
\hline No & \multicolumn{1}{c}{ Base } & $\begin{array}{c}\text { Reduplication position } \\
\text { Initial position reduplicants }\end{array}$ \\
\hline 1 & madah & Mmduh \\
2 & sabil & Salsabil \\
3 & N/A & Cycylya \\
& & Internal position reduplicants \\
4 & hamad & hammad \\
5 & Samar & Sammar \\
6 & Salim & Sallam \\
7 & yamar & Yammar \\
& & Final position reduplicants \\
8 & rafa & Rafif \\
9 & Safa & Safif \\
10 & Saza & Saziz \\
11 & N/A & Lyly \\
\hline
\end{tabular}

In table 6 the personal names collected have been categorized according to the occurrence of reduplication into three positions; initial position, internal position, and final position. The type of reduplication emerged from the personal names collected shows a partial rather than entire reduplication process of base as can be seen in examples 1, 2, 4-7, and 8-10, except for names borrowed from other languages i.e. have no Arabic root such as cycylya and Lyly. That means changes in the internal morpheme's properties could lead to a form of reduplication on which personal names are categorized under non-concatenative languages that allows altering base radicals to create new words (Sa'aida, 2016).

To illustrate, the initial-position reduplicants (i.e. personal names) have been formed through two ways: the reduplication of the first base consonant as in the bolded-underlined bound morpheme mmdu from base form mada in addition to the vowel shifting from a to short vowel 
$\mathrm{u}$. The second way is through the reduplication of the initial consonant-vowel (CV) as in salsabil from the base singular noun sabil where sa has been reduplicated with consonant insertion. For the internal-position reduplicants, they have been formed through the reduplication of the second consonant of the base to the mid position of the formed personal name and maintain the pattern $(\mathrm{CaCCaC})$ such as in the personal names hammad and Sammar from the base verb root hamad and Samar. In the case of the personal name Sallam vowel shifting occured from i to short vowel a and thus stick to the internal position reduplication template as (CaCCaC). The last type emerged is final-position reduplicants where the second consonant of the base root is reduplicated but placed as the last consonant of the reduplicants such as in the personal name rafif, \afif, and \aziz from the base rafa, \afa, and \aza. One more example of the names borrowed from other languages is Lyly where entire reduplication occurred ly+ly. However, these names do not follow any of Arabic templates or derivation structure due to the fact they lack root on which morphological operations occur according to the nature of Arabic language as synthetic non-concatenative. According to Habash et al (2005) these names that have no word's root are foreign borrowed names and thus could not be derivable morphemes.

Personal Names Formed through Inflection Process

TABLE 7. Personal Names Formed Through Pluralization

\begin{tabular}{|c|c|c|c|}
\hline \multirow[t]{2}{*}{ No } & \multirow[t]{2}{*}{ Noun } & \multicolumn{2}{|c|}{ Morphological analysis } \\
\hline & & $\begin{array}{c}\text { Singular personal } \\
\text { name }\end{array}$ & Plural persona name \\
\hline 1 & zahr (blossom) & Zahr & $z u+h w+r$ \\
\hline 2 & najd (plateau) & Najd & $\mathrm{Na}+\mathrm{jw}+\mathrm{d}$ \\
\hline 3 & Sahd (era) & Sahd & Sa+hw+d \\
\hline 4 & waSd (promise) & waYd & $W a+{ } w+d$ \\
\hline 5 & đikra (memory) & Đikra & đikra+ya+aat \\
\hline 6 & Pamjra (princess) & Pamjra & Pamjr+aat \\
\hline 7 & Zaynab & Zaynab & Zaynab+aat \\
\hline 8 & 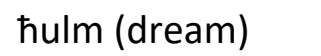 & Hulm & Pa+ћlaam \\
\hline 9 & nafal ( & Nafal & Pa+nfaal \\
\hline
\end{tabular}

Personal names from 1-9 have shown three inflectional processes due to pluralization. Names from 1-4 express pluralization taken place within the root itself and constitute what is known in Arabic as broken plural zamৎ ?altaksiir. This process of pluralization is referred to as internal plural process where changes occurred within the root in its abstract template. For example: waYd is a singular noun with the template CVCC. The personal name formulated has undergone pluralization through infixation i.e. the plural marker waaw in the broken plural form is added to the abstract root template to become CVCCC.

Personal names from 4-9 show that pluralization occurred through inflectional suffixes added to the singular root. This process is called external pluralization process in Arabic where changes occurred to the beginning or end of the root not within as in the case of infixation. However, this

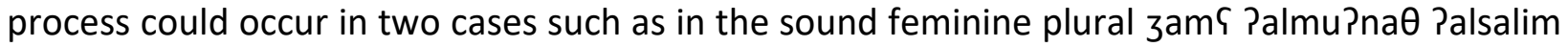
and in the sound masculine plural zamৎ ?almuðakir ?alsalim. The personal names collected show that pluralization has followed the former type that is the sound feminine plural and does not occur in the later type the sound masculine plural. 
To illustrate, the sound feminine plural is formed through the addition of inflectional suffix aat to the singular noun such as in the case of Pamjra: Pamjraat, aat is added to the singular noun Pamjra. However, one personal name shows that the ending short vowel (a) in the singular noun is shifted to (j) before the addition of the sound feminine plural marker aat because sukkun interface as explained earlier is not permitted and also for the ease of pronunciation the shifting took place. This can be found in đikra to đikra+ya+aat where ya is attached to the stem before the inflectional plural suffix aat.

Last type of pluralization found in the corpora of personal names accounts for the vowel change and prefixation of consonant. This plural personal name involves the prefixing of Hamza and alif added to the singular noun and the shifting of the vowel between the second and third consonants to the long aa pattern as can be seen in the plural female personal name $\mathrm{Pa}+\hbar l a a m$ and $\mathrm{Pa}+\mathrm{nfaal}$ from the singular nouns hulm and nafal, respectively.

TABLE 8. Personal Names Inflected for Gender

\begin{tabular}{|c|c|c|}
\hline Male personal name & Female personal name & Name's Structure \\
\hline 3amil & zamila & $+a$ to the male personal name \\
\hline Samir & Samira & \\
\hline saYid & saYida & \\
\hline Wahid & Wahida & \\
\hline mazid & mazida & \\
\hline Common noun (type name) & & Name's denotation \\
\hline Wazin (weight) & Wazin+a & One portion of a weight \\
\hline Ward (flowers) & Ward+a & One flower \\
\hline Ruman (pomegranate fruit) & Ruman+a & One pomegranate \\
\hline Tufaћ ( apple fruit) & Tufah+a & One apple \\
\hline \multicolumn{3}{|l|}{ Masculine adjective } \\
\hline Paћwar & ћawr+a? & bright white girl \\
\hline Payyad & yayd+a? & soft girl \\
\hline
\end{tabular}

The corpora of persona names in table 8 show that feminine personal names are inflected in three ways; by the insertion of feminine morpheme $(+a)$ to their corresponding male personal names; the insertion of same feminine marker but inflected from common noun not male personal names. The denotation of the name is also different as in this category it denotes number of a particular type; the third way is the insertion of another feminine marker alif alta?ni $\theta$ Palmamduda + Hamza to the masculine adjective. The first feminine morphological pattern of inflectional female names is quite common to form female personal names in Arabic. For example, the female personal name zamila is inflected from the masculine name zamil through the insertion of feminine morpheme $(+a)$ which also applicable to names like Samira, saSida, wahida, and mazida.

The second pattern of gender inflection is emerged which indicates gender plus number and classified under the category instance nouns i.e. names that are semantically varied from other female names and morphologically identical as they follow similar inflectional rule of forming female personal names by the insertion of feminine marker to the common noun as can be seen in Wazinta from wazin to mean one amount of quantity and Ward+a from ward to denote 
number of flowers. Also this is applicable for Ruman+a one pomegranate fruit and Tufah+a one apple fruit. The third pattern of female personal names is inflected using the feminine marker alif alta?ni Palmamduda + Hamza added to the masculine adjective i.e. the denotation of the name is similar in male and female names while the only difference between both is the morphological structure of the name as can be seen in hawr+a? the bright white girl from the masculine adjective ?aћwar the bright white boy. The meaning is identical except for variation in the formation of the female name which involves the feminine marker insertion.

\section{Discussion}

At screening stage of the personal names collection, the corpora showed that Jordanian personal names both males and females could be classified according to derivational analysis into four categories: verbal nouns, compounding, diminutivization, and reduplication. Verbal nouns are derived from past verb form which is triliteral root and from present verb form in both quadriliteral and quinquiliteral roots. In the analysis of personal names' internal structure, the root is taken as the basic morphological unit in order to determine the morphological operations emerged during the formation of Jordanian personal names. Moreover, According to Barnabas and Peter (2013) compound personal names have three main categories noun + noun, noun + verb, and noun + adjective. In the current study compound personal names have two forms of noun + noun and noun + preposition + noun. This means that one of the emerged patterns agreed with Barnabas and Peter on the one hand, and a new pattern on the other hand has been discovered which is represented by the insertion of preposition to the second noun as being called the inner noun phrase. Thus, compounding as a morphological pattern would take various shapes in that it might involve a combination of two or more different grammatical constituents of verbs, nouns or adjectives. This is actually obvious as the compound patterns identified in both studies are not similar in two patterns and identical on anther. These personal names could mainly be divided into two groups based on gender, male and female names.

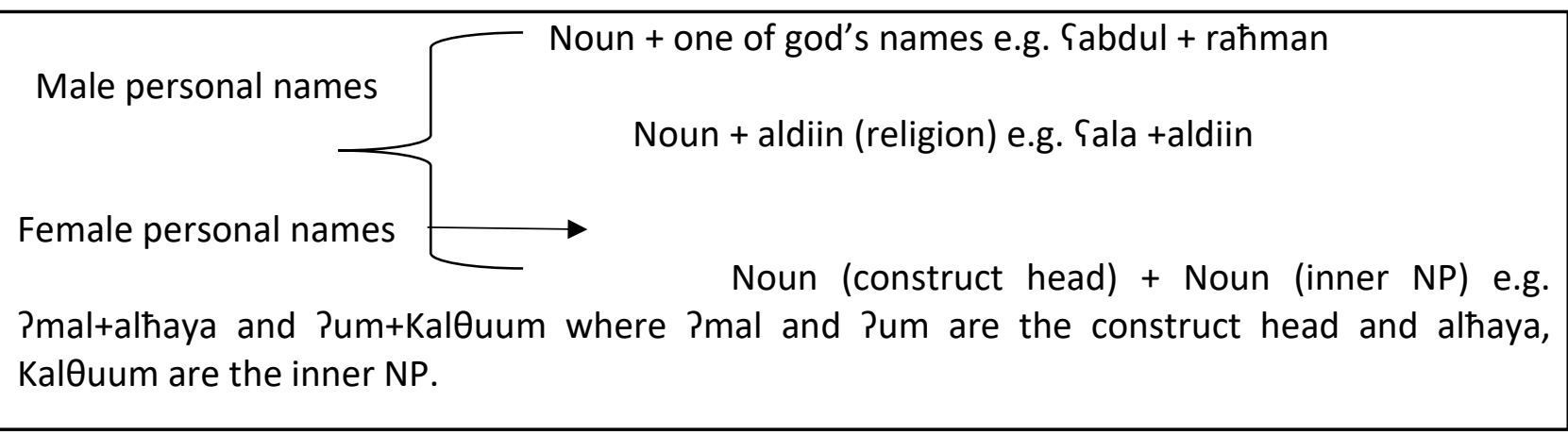

FIGURE 1. Compounding forms in the male and female personal names.

Interestingly, the corpora show that some personal names specifically male personal names are formed through the insertion of the preposition in bi attached to the inner NP construct called "annexor" taken from annexed (Hoyt, 2008 p. 5). Examples are the personal names PalmuStasim biAllah and Palmu?min biAllah where the preposition bi is attached to the inner NP Allah.

Linguistically, diminutive is characterized by the abstract meaning of degradation, smallness, and minimization that majorly operates on nouns and adjectives in Arabic with quite 
little and exceptional cases in verbs (Watson, 2006). Indeed, the diminutivization is universally observed to be mostly applied to nouns (Appiah Amfo and Insaidoo Appah, 2019). However, diminutive personal names are given also on the basis of passionately addressing children by their parents and also by close relative and friends depending on the strength of the relationship between the addresser and the addresses (Yassin, 1978). Therefore, diminutive personal names are meant to the sake of intimacy and endearment by which addresser decrease official treatment and remove social interaction barriers with the addressee. Thus, this morphological pattern as the collected corpora of personal names show could be used for both males and females persons and most often by parents to their children.

Haspelmath and Sims (2010) defines reduplication as "a morphological process which repeats the morphological base entirely or only partially" (p. 274). Therefore, reduplication can be described as a morphological process that is performed to derive new word forms through the extension of the base by means of doubling morphological units. The base refers to the root consonants which constitute the backbone of the various word-forming processes with regards to the stable lexical meaning they convey across the forms derived from the same root (Katamba, 1993 and McCarthy, 1981). As mentioned earlier in chapter two and four, the morphology of Arabic as a non-concatenative system was one of the most well-known languages in which reduplication occupied a big portion of word-formation process in that it is a characteristic of Arabic to replace shorter forms with longer ones (Maas, 2000). Thus, a single consonant can be considered a permitted size of the reduplicant whereas such point is supported by the fact that the size of some morphological morphemes in the ordinary case of affixation can be also bare radical, for example, the $(\mathrm{m})$ consonant represents a morpheme that is prefixed to words in Arabic to create placial nouns like maktab office.

Inflection refers to the process in where affixes are added to the word's root to change its form but simultaneously retains its basic meaning. These affixes could take various forms depending on the language such as in the form of prefix, suffix, and also infix. In other words, inflectional morphemes are bound morphemes that are not attached to the root to produce new words in Arabic language but rather to show aspects of grammatical function a word implies (Yule, 2006). The corpora of personal names collected show that inflection process occurred due to pluralization and following three main types: (1) waaw insertion to the noun's stem (2) yaa replacement to the noun ends with short alif sound before the addition of the inflectional suffix aat that is a plural marker to the sound feminine plural nouns. Waaw and yaa are semiconsonants as they have some vowel's features also in some cases they work as vowels. (3) aat suffix attached to the singular noun stem (4) prefixing the singular noun with a conjunctive Hamza and short vowel (a).

It is worthy to mention that when it comes to the nouns inflected for gender that Arabic language is distinctive from other languages English for instance. The inflectional morphemes used in Arabic to change a word grammatical function from masculine to feminine is not used in English though other inflectional categories are shared such as number and tense. Arabic nouns gender is classified as masculine and feminine and from the point view of morphology masculine forms shaped the simplest and basic form of gender, while feminine nouns have their own inflectional suffix to mark their gender. Although some masculine personal names end with a feminine morpheme in Arabic, but they still considered masculine as this is socially and etymologically attributed than morphologically structured. Actually, these male personal names 
is said to be unreal feminine i.e. they end with a feminine marker and maintain masculine referent.

\section{Conclusion}

This study is mainly focusing on the linguistic aspects of the Jordanian personal names; precisely on the morphological structure of different types of morphemes forming a personal name. While it is quite important to highlight that personal names are widely investigated from a socio-cultural perspective, it is also equally necessary to find the linguistic content of personal names as they are proved to be part of language both morphologically and semantically as the current study demonstrated. Moreover, the study found that Jordanian personal names linguistic patterns can be classified derivationally and inflectionally according to the derivational and inflectional approaches. Initially, based on derivational operations, personal names fall under the categories of verbal nouns; compounding names, diminutives; and reduplicants. On the other hand, inflectional processes involve two patterns identified from the collected corporal of personal names as pluralization and names inflected for gender. To elaborate, in the process of describing all patterns emerged, word's root is the basic unit of analysis which is identified as a morpheme stored in the lexicon of Arabic language. This in turn supports the nature of non-concatenative language, Arabic is meant here, that root is a morpheme and other affixations are operations applied at other stages to the root to form new words. Finally, It could be concluded that personal names in Jordanian Arabic are linguistic entities and part of people's daily lexicon that adhere to the linguistic rules and internal structure of the language to which the analysis is based. It is important to highlight that the current paper has dealt with both male and female personal names, future research may compare female with male name patterns, to cross tabulate name against age for instance, to examine ethnic and racial variables, to have a look at relationships among social class, and education as well.

\section{References}

Anindo, C. (2016). A morphosemantic study of toponyms: Lulogooli place names.

Amfo, A. N. A., \& Appah, I. C. K. (2019). Lexicalization of Akan Diminutives: Form, Meaning and Motivation. Linguistik online, 94(1).

Aronoff, M., and Fudeman, K. (2010). What is Morphology? 2nd Edn. London: Wiley -Blackwell.

Barnabas, L., \& Peter, J. (2013). A Morphosemantic Analysis of the Kamue Personal Names. International Journal of English Language and Linguistics Research, 1(2), 1-12.

Bybee, J. L. (1988). Morphology as lexical organization. Theoretical morphology, 119141.

Comrie, B. (1989). Language universals and linguistic typology: Syntax and morphology. University of Chicago press.

El Zarka, D. (2005). On the borderline of reduplication: gemination and other consonant doubling in Arabic morphology. Studies on Reduplication Y, 369, 393.

Endang, S. N. (2014). The analysis of derivational and inflectional Morphemes in Lyric of songs Adele Albums,School of Teacher Training and Education, Muhammadiyyah University of Surakarta, 2014.

Fromkin, V., Rodman, R., \& Hyams, N. (2007). An Introduction to Language . Boston, MA: Thomson Wadsworth. 
Habash, N., Rambow, O., \& Kiraz, G. (2005). Morphological analysis and generation for Arabic dialects. In Proceedings of the ACL Workshop on Computational Approaches to Semitic Languages (pp. 17-24).

Haspelmath, M., and Sims, A. (2010). Understanding Morphology .2nd Edn. New York: OUP.

Harrama, A. M. (1993). Libyan Arabic morphology: Al-Jabal dialect. PhD dissertation, The University of Arizona.

Hoyt, F. (2008). The Arabic noun phrase. The Encyclopedia of Arabic Language and Linguistics. Leiden: Brill.

Hurch, B., \& Mattes, V. (2005). Über die Entstehung von partieller Reduplikation. Sprache und Natürlichkeit: Gedenkband für Willi Mayerthaler, 483, 137.

Katamba, F. (1993). Morphology. New York: St.

Maas, U. (2000). Moroccan: a language in emergence. Arabic as a minority language, 383-404.

Marantz, A. (1982). Re Reduplication', Linguistic Inquiry13, 435-482. Marantz43513Linguistic Inquiry1982.

McCarthy, J. J. (1981). Formal problems in Semitic phonology and morphology. Linguistics Department Faculty Publication Series, 39.

Muhammad, M. E. (2006). From the treasures of arabic morphology. Zam Zam Publishers.

O'grady, W., Dobrovolsky, M., Katamba, F. (1996).Comtemporay Linguistics: An Introduction. Longman: Pearson

Ryding, K. C. (2005). A reference grammar of modern standard Arabic. Cambridge university press.

Sa'aida, Z. (2016). Expanding the lexicon: The case of Jordanian Arabic. Advances in Language and Literary Studies, 7(6), 9-14.

Watson, J. C. (2006). Arabic morphology: diminutive verbs and diminutive nouns in San'ani Arabic. Morphology, 16(2), 189-204.

Widdowson, H. G. (1996). Linguistics. Oxford University Press.

Yassin, M. (1978). Personal names of address in Kuwaiti Arabic. Anthropological Linguistics, 20(2), 53-63. 